\title{
Investigation of mixed mode fatigue crack propagation in SEN-specimen under in-phase and out-of-phase conditions due to tension- compression and torsional loading
}

\author{
Paul Koester ${ }^{1,1}$, Christopher Benz ${ }^{1}$, and Manuela Sander ${ }^{1}$ \\ ${ }^{1}$ University of Rostock, Institute of Structural Mechanics, Albert-Einstein-Str. 2, 18059 Rostock, \\ Germany
}

\begin{abstract}
Numerous cases of damage by fatigue in structures are related to mechanical stresses due to mixed mode loading conditions. To prevent such cases of failure a precise knowledge of the corresponding theoretical background is indispensable. Unfortunately, it is not yet possible to describe the crack propagation considering a superposition of all three crack modes satisfactory. For this purpose, experiments on single-edge notched specimens made of 34CrNiMo6 using a tension-torsion testing machine under different mixed mode ratios and phase angles were performed. The focus of the investigations is especially on the kinking and the twisting angle of the crack as well as on the influence on the residual lifetime. Further, existing concepts concerning the prediction of the crack growth under mixed mode are evaluated.
\end{abstract}

\section{Introduction}

In general, structures are subjected to a complex service loading. Due to this and/or the orientation of the fatigue crack in the component a plane or spatial mixed mode loading exists. Furthermore, there are numerous practical cases where the loading and thus the dominating fracture modes change with time and location during fatigue crack propagation. For predictions of the service life of a component as well as for the evaluation of safety during operation, a profound knowledge base of the respective influences is essential. Most of the investigations presented in literature focus on mode I/II or mode I/III loading conditions. However, it is not yet possible to describe the crack propagation considering all three crack modes satisfactory.

Within the scope of this paper the influence of a superposition of mode I, II and III under different conditions on the crack propagation is investigated. Therefore, systematic experimental examinations on the crack growth in flat specimens using a tension-torsion testing machine were performed. In particular, the kinking and the twisting angle as well as the residual life time due to different phase angles and mixed mode ratios are investigated. 
Furthermore, the experimental investigations are accompanied by linear-elastic finite element simulations for the evaluation of existing concepts concerning the prediction of the crack growth under mixed mode conditions. The main focus is on a better understanding of the basic phenomenon of the fatigue in structural elements.

\section{Material, specimen geometry and testing machine}

The tested material is the high-strength steel 34CrNiMo6 at quenched and tempered conditions with the chemical composition shown in Table 1 and the mechanical properties shown in Table 2. The specimens are cut and CNC milled out of a forged block instead of a sheet metal to prevent for influences due to possible rolling directions. Single-edge notched (SEN) specimens with the dimensions presented in Fig. 1a are used.

For comparable and reproduceable conditions a V-shaped sharp starter notch is wireeroded. Furthermore, an initial crack under mode I is inserted with a crack increment of $\Delta a=0.3 \mathrm{~mm}$ which is corresponding to a potential drop by one percent concerning the potential drop technique. The experiments are performed with a servo-hydraulic testing machine Tension/Torsion Instron 8854 (Fig. 1b).

Table 1. Chemical composition (in \% of weight) of the tested material 34CrNiMo6 [1].

\begin{tabular}{lccccccccc}
\hline Element & $\mathrm{C}$ & $\mathrm{Mn}$ & $\mathrm{Si}$ & $\mathrm{P}$ & $\mathrm{S}$ & $\mathrm{Cr}$ & $\mathrm{Mo}$ & $\mathrm{Ni}$ & $\mathrm{Al}$ \\
\hline Composition & 0,36 & 0,73 & 0,26 & 0,006 & 0,001 & 1,57 & 0,22 & 1,57 & 0,022 \\
\hline
\end{tabular}

Table 2. Mechanical properties of the tested material 34CrNiMo6 [1].

\begin{tabular}{cccccc}
\hline $\begin{array}{c}R_{\mathrm{p} 0,2} \text { in } \\
\mathrm{MPa}\end{array}$ & $\begin{array}{c}R_{\mathrm{m}} \text { in } \\
\mathrm{MPa}\end{array}$ & $A_{5}$ in $\%$ & $\begin{array}{c}\text { Hardness } \\
\text { in HB }\end{array}$ & $E$ in MPa & $v$ \\
\hline 819 & 963 & 15 & 326 & 210.000 & 0,3 \\
\hline
\end{tabular}

a)
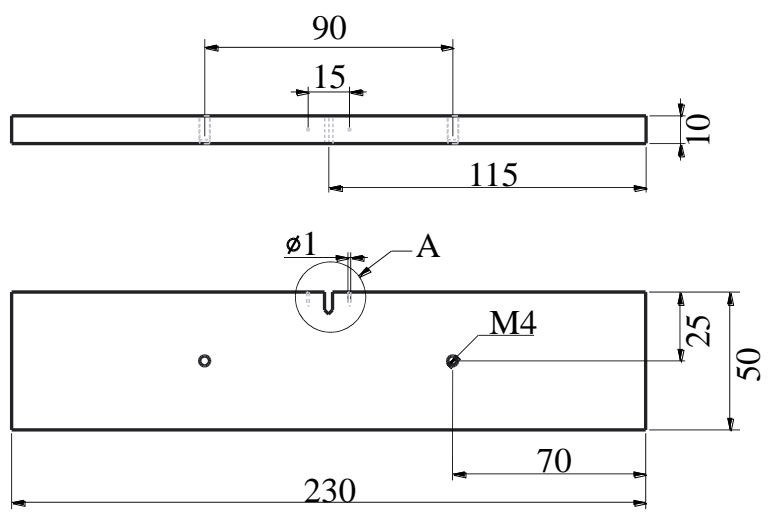

Detail A

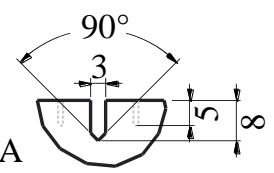

b)

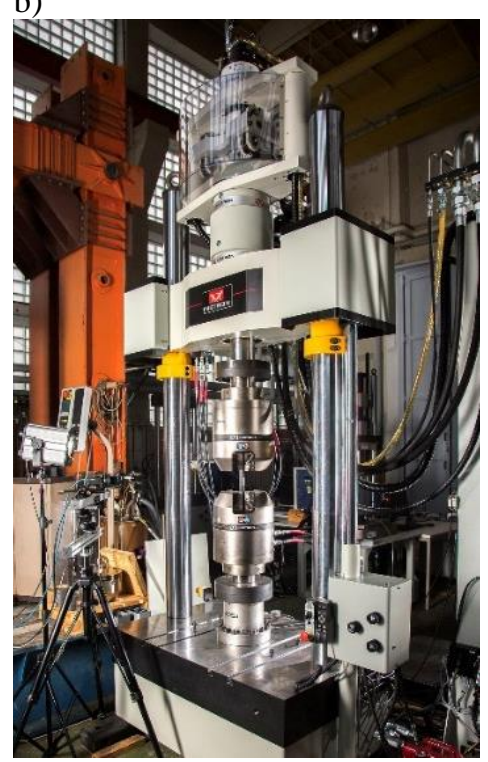

Fig. 1. Experimental setup [1]

a) Drawing of the SEN(TC)-specimen

b) Servo-hydraulic testing machine Tension/Torsion Instron 8854 . 


\section{Experimental investigations}

The main focus of the investigations is on the influence of superimposed cyclic tensioncompression and torsional loading including all three crack modes on the crack propagation. However, since the processes of crack growth under mixed mode loading conditions are very complex experimental tests under simplified conditions are performed previously.

In Fig. 2a one of the crack surfaces of a specimen loaded under separate, cyclic torsion at $R=-1$ is presented. It becomes clear that the crack does not grow in the horizontal symmetry plane but under a high kinking angle of nearly $\varphi_{0}=70^{\circ}$, which is typical for mode II cracks. Moreover, the kinking angle is equal on the front and the back side of the specimen (Fig. 2b and c). Regarding the twisting angle $\psi_{0}$ along the depth of the specimen there is a change of direction in the vertical symmetry plane. This leads to a V-shaped crack path until the final failure (Fig. 2d).

a)

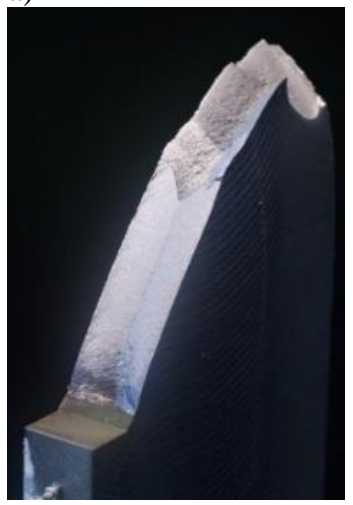

b)

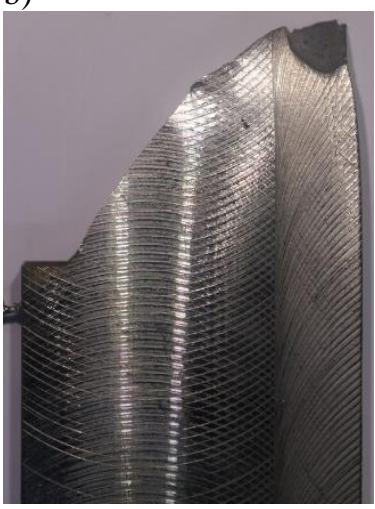

c)

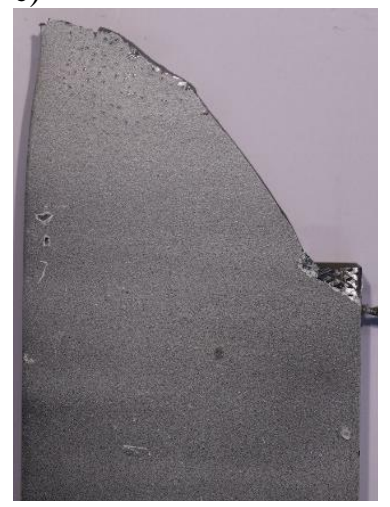

d)

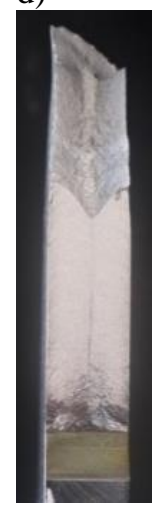

Fig. 2. Crack surface after cyclic loading under separate torsion at $R=-1$ [1]

a) Diagonal view

b), c) Front and back side of the specimen

d) Straight view on the crack surface.

As an alternating loading involves additional complications in particular with regard to friction further tests are performed under torsional loading at $R=0.1$ superposed with a static tension. The corresponding crack surfaces for a tensile loading of $5 \mathrm{kN}$ and of $10 \mathrm{kN}$ are presented in Fig. 3.

In comparison to the results after separate torsional loading the crack surfaces show a significantly changed crack propagation. The kinking angle is smaller (Fig. 3a) and decreases with increasing mode I (Fig. 3c). It could also be observed that the crack grows in opposite directions on the specimen surfaces in the beginning. After a few millimetres of crack propagation, there is suddenly a change of direction on one of both sides, so that afterwards the kinking angles at the surfaces have the same sign.

The twisting angle does not follow a V-shaped development, but rather an S-shaped propagation with a linear increase in the middle section at those loading conditions (Fig. 3b and d). Furthermore, the crack path increases slightly with higher crack depth, but is not significantly influenced by the amount of the mode I loading part. 
a)

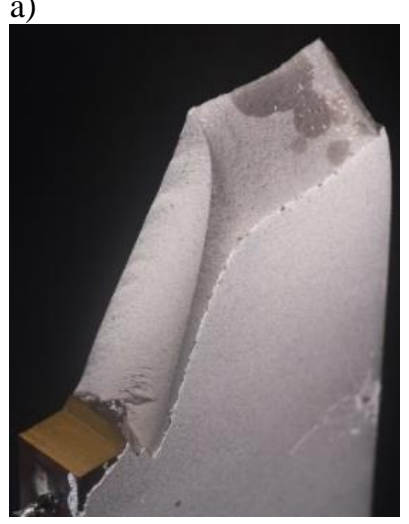

b)

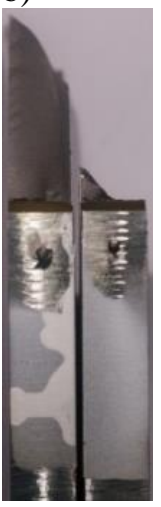

c)

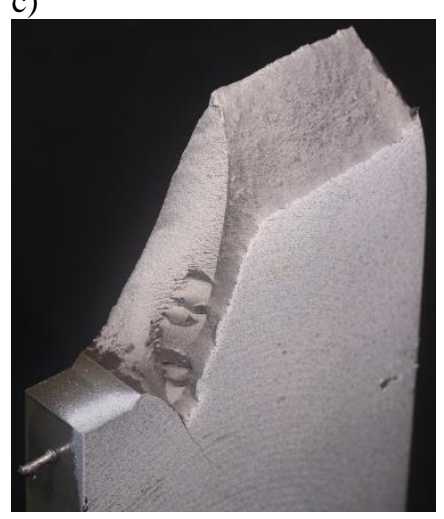

d)

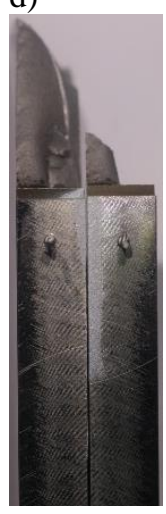

Fig. 3. Crack surfaces after superposition of cyclic torsional loading at $R=0.1$ with [1]

a) a static tensile loading of $F=5 \mathrm{kN}$ and

b) a static tensile loading of $F=10 \mathrm{kN}$.

Based on the results of the previous investigations a load level of $\sigma_{\mathrm{N} \text {, max }} / \sigma_{\mathrm{F}}=0.08$ is defined. Further, the $R$-ratio of the torsional loading as well as of the axial loading was set to $R=-1$. Following those conditions, different mixed mode ratios calculated from the maximum nominal stresses $\tau_{\mathrm{N}} / \sigma_{\mathrm{N}}$ are tested.

At a mixed mode ratio of $\tau_{\mathrm{N}} / \sigma_{\mathrm{N}}=1 / 1$ the kinking angle is merely smaller (Fig. 4a) than in the experiments under separate torsion (Fig. 2a). Moreover, the kinking angle is clearly smaller at a ratio of $\sqrt{3} / 3$ (Fig. $4 \mathrm{~b}$ ), because of the higher mode I part of the loading. Apart from this, it is noticeable that the crack branches at a ratio of $1 / 1$, while it is not observable at a ratio of $\sqrt{ } 3 / 3$.

The observations regarding the kinking angles can also be seen by looking at the final crack surfaces (Fig. 4c and d). Furthermore, it is conspicuous that friction effects have a major influence on the crack shape developments. The interaction of both alternating loading types leads to a heavy abrasion and therefore to a darker and rougher crack surface.

Concerning those conditions, a twisting angle is hard to determine, but its crack path corresponds more closely the S-shaped example in Fig. 3 than the one at separate torsional loading with $R=-1$ (Fig. 2).

a)

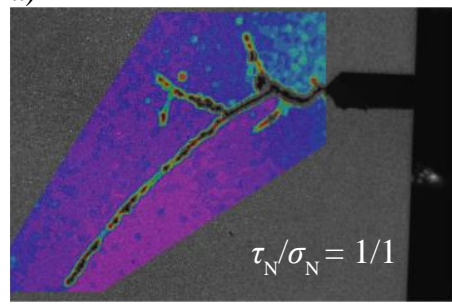

b)

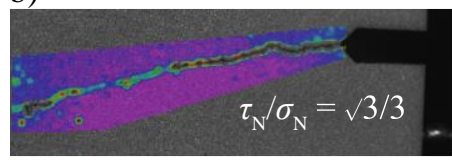

c)

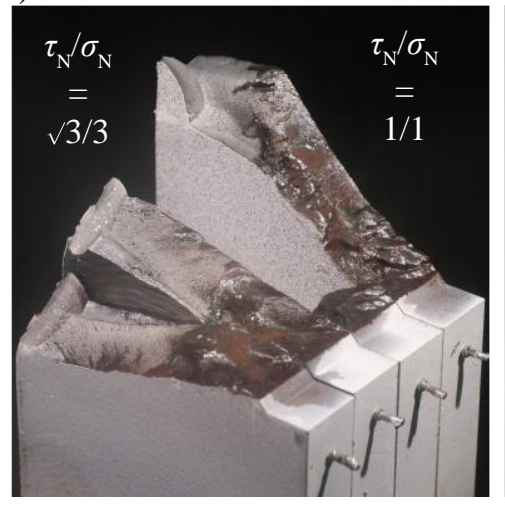

d)

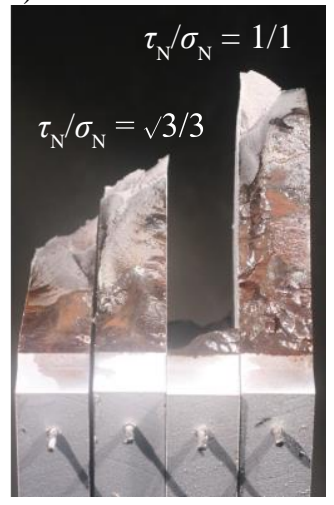

Fig. 4. Crack propagation under in-phase loading conditions with different mixed mode ratios a), b) Crack propagation observed with digital image correlation (DIC)

c), d) Comparison of the crack surfaces [1]. 
In Fig. 5 the results of the appropriate experiments under $90^{\circ}$ phase shifted loading conditions are shown. It becomes clear that the crack does not branch at $\tau_{\mathrm{N}} / \sigma_{\mathrm{N}}=1 / 1$ (Fig. 5a). In addition, in this example the kinking angle is smaller than under in-phase conditions, while there is no significant change at a ratio of $\sqrt{3} / 3$ (Fig. $5 b$ ).

Regarding Fig. $5 \mathrm{c}$ it is noticeable that the effect of friction is lower under out-of-phase conditions, resulting in brighter and finer crack surfaces. The twisting angle has a nearly complete linear path across the thickness of the specimen (Fig. 5d) and again slightly increases with increasing crack depth.

a)

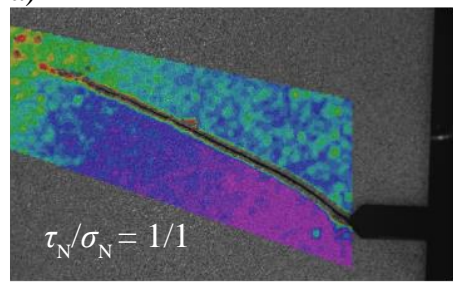

b)

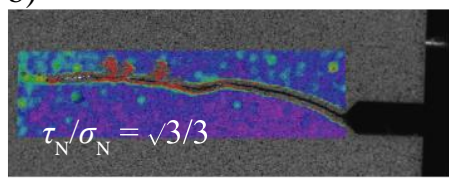

c)

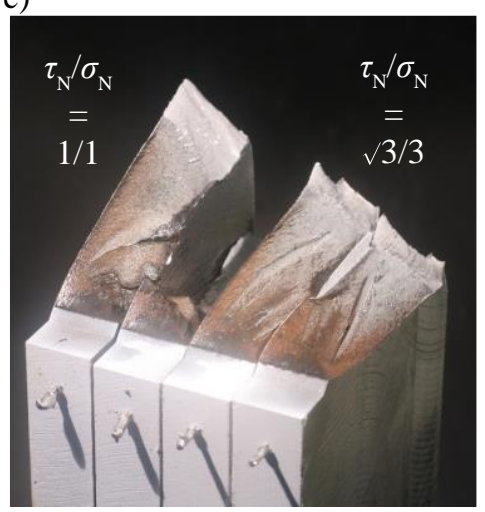

d)

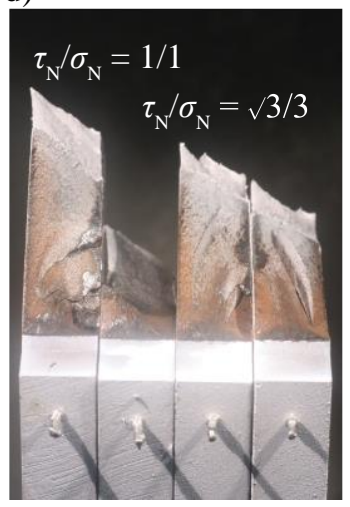

Fig. 5. Crack propagation under $90^{\circ}$ phase shifted loading conditions

a), b) Crack propagation observed with digital image correlation (DIC)

c), d) Comparison of the crack surfaces [1].

The diagram in Fig. 6 shows the crack length $a$ versus the number of cycles $N$. Presented is each one exemplary test for conditions under both mixed mode ratios as well as under a phase shift angle of $\varphi=0^{\circ}$ and $90^{\circ}$. It can be seen that there is an influence on the crack growth rate depending on the chosen loading conditions. While the crack growth rate decreases with a higher amount of mode I at in-phase conditions, it increases at $90^{\circ}$ out-ofphase conditions. All in all, the highest crack growth rate reveals at a mixed mode ratio of $1 / 1$ and $\varphi=90^{\circ}$. On the other hand, the smallest crack growth rate is also given at a ratio of $1 / 1$, but under in-phase conditions. The curves at $\tau_{\mathrm{N}} / \sigma_{\mathrm{N}}=\sqrt{3} / 3$ only differ marginally.

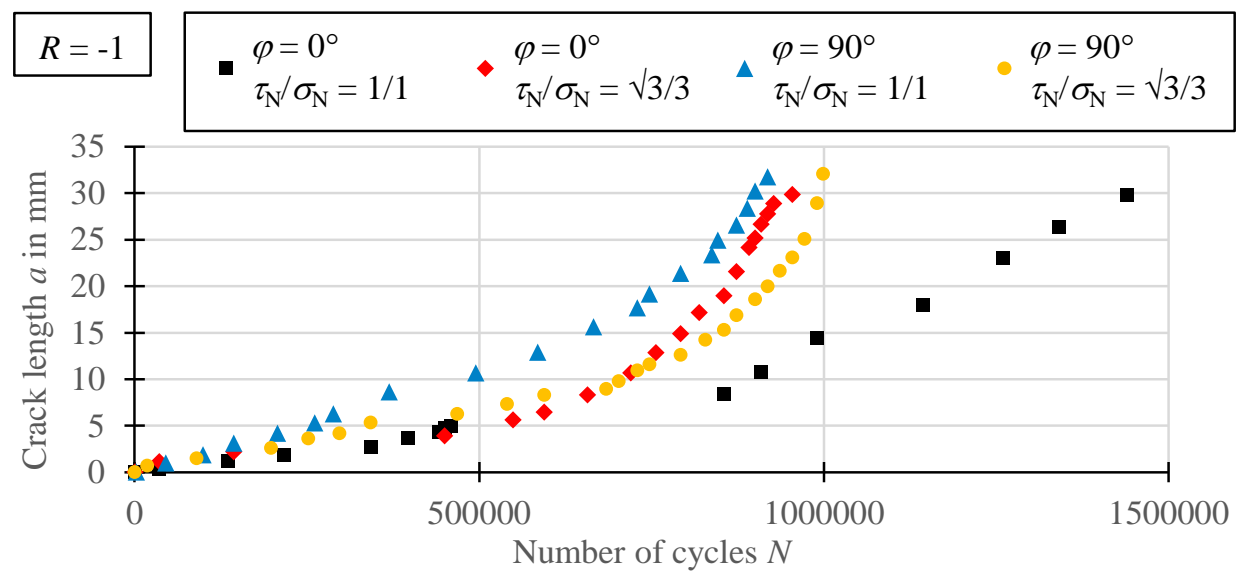

Fig. 6. Exemplary $a$ versus $N$ plots for different phase angles and mixed mode ratios. 
Additionally to the previous experiments, further investigations at the same mixed mode ratios, but with a phase shift angle of $45^{\circ}$ were performed. The comparison of the crack surfaces in Fig. 7a reveal that the kinking angles are very small and even smaller than at $\varphi=90^{\circ}$. Moreover, there is no significant difference between the results of the both different $\tau_{\mathrm{N}} / \sigma_{\mathrm{N}}$-ratios.

Regarding the residual lifetimes for all test series, it becomes clear that the number of cycles to failure decreases with increasing phase shift angle (Fig. 7b). However, this influence is significant lower at a mixed mode ratio with higher mode I part.

a)

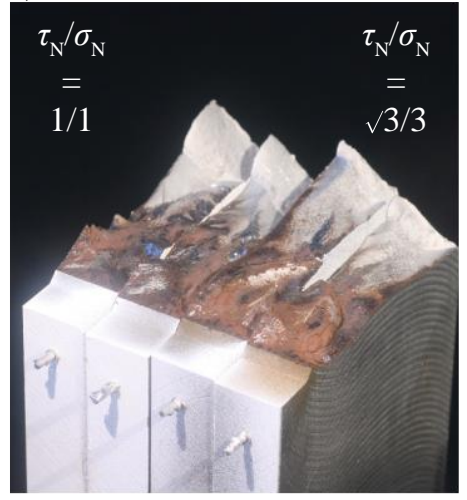

b)

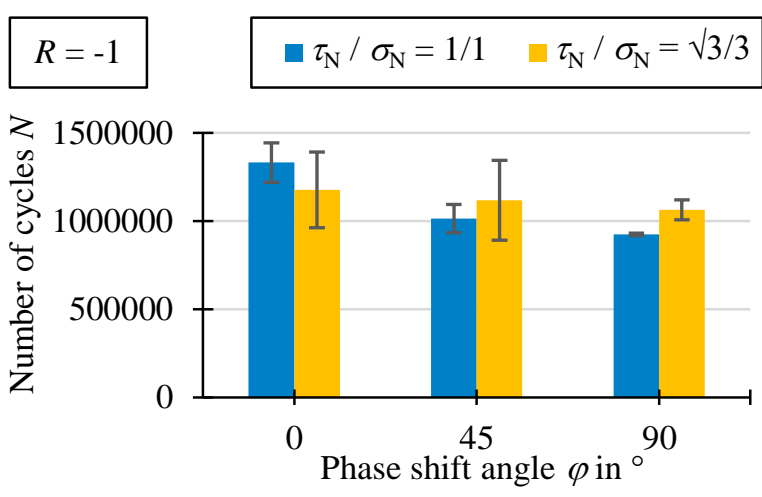

Fig. 7. Comparative examinations under $45^{\circ}$ phase shifted conditions

a) Crack surfaces after $45^{\circ}$ phase shifted loading under different mixed mode ratios

b) Number of cycles to failure versus the phase angle and mixed mode ratio.

\section{Numerical investigations}

As mentioned, the theoretical description of the crack propagation under mixed mode is not possible satisfactory. Within the scope of this paper, selected concepts are analysed and comparatively discussed in particular concerning the kinking angles. The focus is on the MTS- [2] and MSS-criteria [3-7] as well as their enhancements by HABOUSSA et al. [8] or rather $C H A O$ and $L I U$ [9], the $\sigma_{1}^{\prime}$-criteria called concept by SCHÖLLMANN et al. [10-14] and the equivalent stress intensity factor by RICHARD et al. [12-17].

For the investigations a FE-model of the SEN-specimen is created in ABAQUS, which contains a plane initial crack with a straight crack front with $\Delta a=4 \mathrm{~mm}$. Furthermore, a superimposed loading at $R=0$ with $\mathrm{F}_{\max }=30 \mathrm{kN}$ and $\mathrm{M}_{\mathrm{T}, \max }=224 \mathrm{Nm}$ is applied. On the basis of these conditions the calculated kinking angles for each concept are shown in Table 3.

Table 3. Kinking angles $\varphi_{0}$ in degrees depending on the position on the crack front [18].

\begin{tabular}{ccccccccc}
\hline $\begin{array}{c}z \text { in } \\
\text { mm }\end{array}$ & MTS & $\begin{array}{c}\text { MTS } \\
\text { HABOUS- } \\
\text { SA et al. }\end{array}$ & $\begin{array}{c}\text { RICHARD } \\
(2 \mathrm{D})\end{array}$ & MSS & $\begin{array}{c}\text { MSS } \\
\text { HABOUS- } \\
\text { SA et al. }\end{array}$ & $\begin{array}{c}\text { MSS } \\
\text { CHAO },\end{array}$ & $\begin{array}{c}\text { SCHÖLL- } \\
\text { MANN }\end{array}$ & $\begin{array}{c}\text { RICHARD } \\
\sigma_{1}{ }^{*}\end{array}$ \\
\hline 1,0 & $-56,42$ & $-56,42$ & $-60,81$ & 12,63 & 42,82 & 8,23 & $-54,60$ & $-47,51$ \\
5,0 & 0,01 & 0,01 & 0,01 & $\pm 70,50$ & $-70,68$ & $-28,47$ & 0,00 & 0,00 \\
9,0 & 56,43 & 56,43 & 60,82 & $-12,63$ & $-42,81$ & $-13,77$ & 54,60 & 47,51 \\
\hline
\end{tabular}

The results for both MTS-criteria as well as the concepts of SCHÖLLMANN et al. and RICHARD et al. only show slight deviations, whereas the data from the different MSScriteria vary noticeable. On the one hand, the kinking angles at the specimen surface 
calculated by the MSS-criteria based on HABOUSSA fit the results of the MTS-criteria, $S C H O ̈ L L M A N N$ et al. and RICHARD et al., but have opposite signs. On the other hand, the angles of the common MSS-criteria and of the concepts of CHAO and LIU are significantly smaller. Additionally, those three criteria have completely different values in the middle of the specimen. A reason for that is given by a different weighting of the normal and shear load as a result of the criteria approach.

Among the analysed criteria merely the concepts of SCHÖLLMANN et al. and RICHARD et al. (3D) consider all three crack modes and give formulas for the twisting angle simultaneously. For the following investigation the $\sigma_{1}$ '-criteria is of main interest. In this, a crack growth in two steps each of $\Delta a=3 \mathrm{~mm}$ is modelled manually with major simplifications. Both new crack fronts are then evaluated with regard to the kinking and the twisting angles. The numerical result is shown in Fig. 8a compared with the crack surface of the appropriate experiment in Fig. 8b.

a)
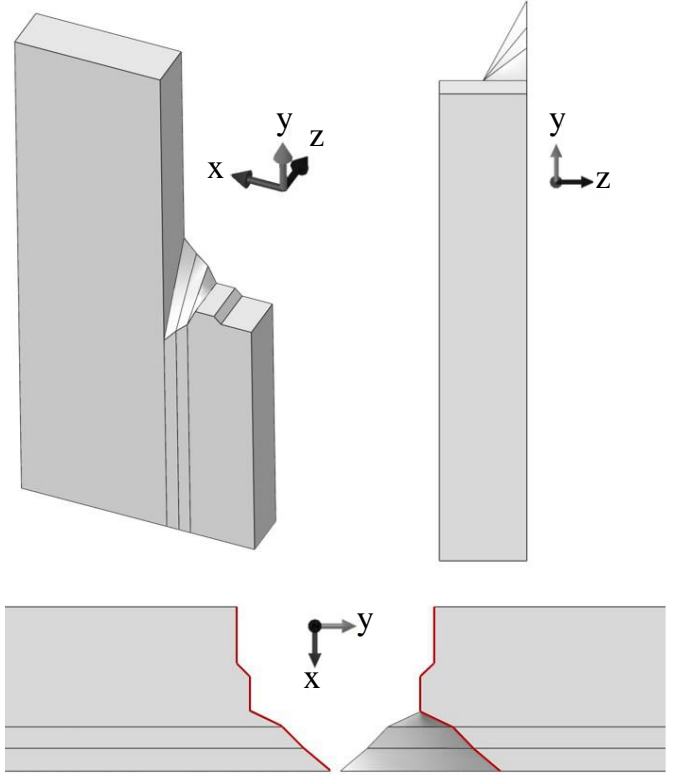

b)
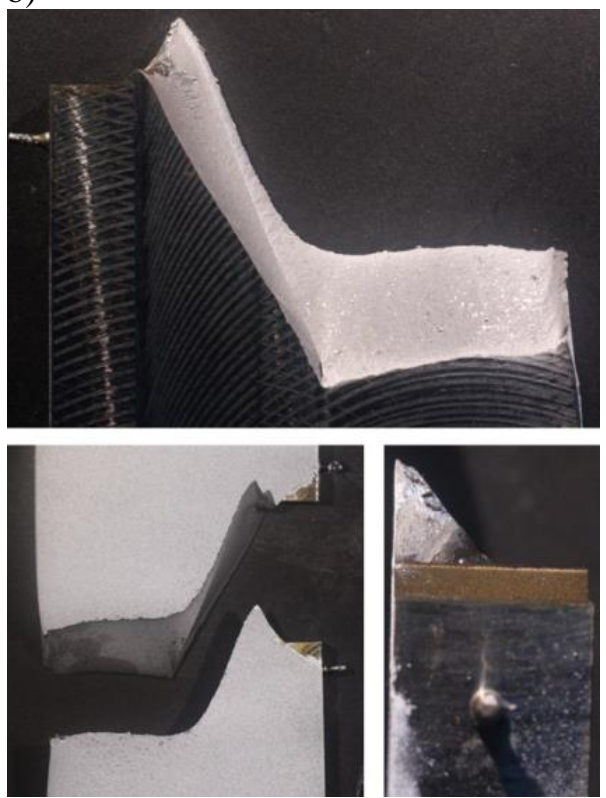

Fig. 8. Comparison of the results concerning the crack propagation from [18]

a) the FE-model and

b) the experiment.

The comparison clearly reveals a good agreement of the kinking angles in the beginning. This also applies for the crack path of the twisting angle along the specimen depth, even if it only follows by the linear connection of the crack tip nodes on the specimen surfaces. However, the one-sided change of direction of the kinking angle cannot be reproduced by the criteria. Further investigations on appropriate simulations following fewer assumptions as well as including the very important contact of the flanks of the crack are in progress to confirm and extend the present results. 


\section{Conclusion and outlook}

A better understanding regarding the phenomenon of the fatigue crack growth concerning all three crack modes is essential. Therefore, appropriate fracture mechanical investigations were implemented to obtain further basic knowledge. The experimental und numerical results can be summarised as follows:

a) Tests under different torsional loading conditions were performed for reference purposes.

b) Numerous experiments under superimposed tension-compression and torsional loading at $R=-1$, different phase shift angles $\varphi$ and mixed mode ratios $\tau_{\mathrm{N}} / \sigma_{\mathrm{N}}$ have shown that there is a significant influence on the kinking and twisting angles as well as on the crack growth rate and residual lifetime.

c) Further, the friction effects are of great importance.

d) Numerical investigations on the crack growth under mixed mode conditions were carried out on the basis of selected existing criteria and have shown that the reproduction of the experiments is merely possible subjected to restrictions.

In the course of the investigations, further tests will be implemented for the verification of additional influences as well as for statistical reasons. Moreover, a precise measurement of the crack surfaces is planned. Finally, further verifications, validations and - if applicable - adjustments of the existing concepts are in progress.

The authors gratefully acknowledge the financial support of this research project SA 960/9-1 provided by the German Research Foundation (DFG) in Bonn, Germany.

\section{References}

1. P. Köster, M. Sander. Untersuchung der Rissausbreitung in Flachproben bei phasengleicher und phasenverschobener Zug/Druck- und Torsionsbelastung. DVMBericht, 251: 149-158 (2019)

2. F. Erdogan, G. C. Sih. On the crack extension in plates under plane loading and transverse shear. ASME J. Basic Eng., 85D: 519-527 (1964)

3. N. Hallbäck, F. Nilsson. Mixed-mode I/II fracture behaviour of an aluminium alloy. J. Mech. Phys. Solds, 42: 1345-1374 (1994)

4. T. M. Maccagno, J. F. Knott. The low temperature brittle fracture behaviour of steel in mixed modes I and II. Eng. Fract. Mech., 38: 111-128 (1991)

5. T. M. Maccagno, J. F. Knott. The mixed mode I/II fracture behaviour of lightly tempered HY130 steel at room temperature. Eng. Fract. Mech., 41: 805-820 (1992)

6. T. M. Maccagno, J. F. Knott. The fracture behaviour of PMMA in mixed modes I and II. Eng. Fract. Mech., 34: 65-86 (1989)

7. S. Liu, Y. J. Chao, X. Zhu. Tensile-shear transition in mixed mode I/III fracture. Int. J. Solids Struct., 41: 6147-6172 (2004)

8. D. Haboussa, T. Elguedj, B. Leblé, A. Combescure. Simulation of the shear-tensile mode transition on dynamic crack propagations. Int. J. Fract., 178: 195-213 (2012)

9. Y. J. Chao, S. Liu. On the failure of cracks under mixed-mode loads. Int. J. Fract., 87: 201-224 (1997)

10. M. Schöllmann. Vorhersage des Risswachstums in ebenen und raumlichen Strukturen mittels numerischer Simulation. Fortschritt-Berichte VDI (VDI-Verlag, Düsseldorf, 2001) 
11. M. Schöllmann, H. A. Richard, G. Kullmer, M. Fulland. A new criterion for the prediction of crack development in multiaxially loaded structures. Int. J. Fatigue, 117: 129-141 (2002)

12. H. A. Richard, B. Schramm, N.-H. Schirmeisen. Cracks on Mixed Mode loading Theories, experiments, simulations. Int. J. Fatigue, 62: 93-103 (2014)

13. D. Rozumek, E. Macha. A survey of failure criteria and parameters in mixed-mode fatigue crack growth. J. Mater. Sci., 45: 190-210 (2009)

14. H. A. Richard, M. Fulland, M. Sander. Theoretical crack path prediction. Fatigue Fract. Eng. M., 28: 3-12 (2005)

15. H. A. Richard, Bruchversagen bei überlagerter Normal- und Schubbeanspruchung von Rissen (VDI-Verlag, Düsseldorf, 1985)

16. H. A. Richard, F. G. Buchholz, G. Kullmer, M. Schöllmann. 2D- and 3D-Mixed Mode Fracture Criteria. Key Eng. Mater, 251-252: 251-260 (2003)

17. H. A. Richard, M. Fulland, F. G. Buchholz, M. Schöllmann. 3D Fracture Criteria for Structures with Cracks. Steel Res. Int., 74: 491-497 (2003)

18. S. Mallow, Untersuchung verschiedener Rissausbreitungskonzepte bei Mixed-Mode Belastung an geklemmten Seitenrissproben unter Anwendung der Finite Elemente Methode (Universität Rostock, Rostock, 2018) 